\title{
The Investigation of the Relationship Between the Risk Management With Creation and the Entrepreneurship of Erzurum Sport Staffs
}

\author{
Gul Eda Burmaoglu \\ Correspondence: Gul Eda Burmaoglu, Faculty of Sport Sciences, Ataturk University, Erzurum, Turkey.
}

Received: June 25, 2018

doi:10.11114/jets.v6i4a.3426
Online Published: July 9, 2018

URL: https://doi.org/10.11114/jets.v6i4a.3426

\begin{abstract}
The purpose of this study was to determine the relationship between risk management with creativity and Entrepreneurship of Erzurum sport staffs. The methodology of this research is descriptive correlational one. All employees of Erzurum sport staffs, $(n=82)$ participated in this research. To collect the data, 3 questionnaires were used: risk management, creativity and entrepreneurship. Spearman correlation coefficient was used to get the results. The results showed that there is a significant positive relationship between risk management, with creativity and entrepreneurship of Erzurum sport staffs and among components of risk management, risk monitoring component is able to predict creativity, as well as the components of risk management.
\end{abstract}

Keyword: risk management, innovation, entrepreneurship

\section{Introduction}

The risk management is the new branch of the management science. This new science is growing rapidly regardless with its newness and being considered by many various managers and specialists. Today, the risk and its related different tendencies such as the risk studies, risk evaluation and risk analysis have been established in many various subjects such as the financial and credit-based and investment affairs, commerce, insurance, security and safety, health and treatment, industrial and construction projects and even political and social as well as military issues. For the reason, the year 2007 has been considered as the commerce tendency going towards the risk management. The results of studies have shown that about $46 \%$ of the commercial institutions in the US have been implemented by the risk management technologies efficiently and these are also going to optimize and reevaluate the next generation technologies potentially (Singh \& Surujlal, 2010). Also, the risk management is one of the most sophisticated managerial approaches that it has been applied in many organizations in order to optimize and increase the organizational effectiveness. The completion and implementation of the risk management policies into organizations can conduct and facilitate the resources and facilitations towards the purpose and this can also increase the effectiveness of creative and innovative activities in this pavement. The risk management is the most convenient and reasonable process of the management to recognize, analyze, evaluate, reflect and control the risk of operations and tasks; the main aim is also subjected to reduce the harmful events trying to maximize all opportunities in this case. Today, the main aim of the risk management is not merely subjected to reduce the risk; in other words, the main purpose of the risk management is not to prevent the risk but also it tries to capture all opportunities in this pavement (Culp et al, 2001). The completion of the risk is not merely subjected to the misuse of something because in many various conditions, the risk should be carried out to be benefitted in this regard. The process of change is only being carried out by the risk (Baum \& Smith, 2010). In summary, the risk is mainly pointing to the investment coming from the opportunity concept. In other words, the risk allocation is mainly relied on the efficacy of something highly. The construction and application of opportunities is roughly subjected to the basic concepts of the entrepreneurship and these kinds of opportunities will be coming along with some risks in this pavement. The higher expectation of the efficacy from the common activities has been made the entrepreneurship to confront with many various challenges (Hassas Yeghaneh et al, 2002). Indeed, the entrepreneurship is a risky person purchasing all commodities and services with certain prices but selling with unclear prices. In other words, this person has to produce some factors in order to produce and commerce or give the services towards the same entrepreneurship and it will be called "entrepreneurship" in this pavement. The entrepreneurship is a process that it uses all creative, innovative and new elements in order to apply these mentioned factors for obtaining the related resources in this pavement (the same). On the other hand, the entrepreneurship culture is subjected to accept all risks following the suitable opportunities and meeting the requirements through the innovation and establishment of job affairs (Baum \& 
Smith, 2010). Max Weber in the representation of the new industrial civilization formation and investment in the west points to the fact that this concept is subjected to the same entrepreneurship culture today; Weber considers the entrepreneurship culture development rooting from four main factors of praising to work for happiness, risk-ability for changing the destiny, planning for future and saving issues (Baum \& Smith, 2010). Indeed, one of the most sophisticated features of the entrepreneurship is subjected to the entrepreneurship literature considering the risk ability of people in this process. In fact, the entrepreneurship are subjected to those people that they have got independence-seeking temperament and creation and they are also ready to accept the responsibility of all affairs in this pavement. The entrepreneurship is more self-responsible, autonomous trying to make risky events (Mootana et al, 2010). This entrepreneurship should be more responsible for achieving risky tasks; that is, they are more ready to fight against all different conditions trying to change the situations for their own benefit potentially. For the reason, the government should support all these entrepreneurships providing the different conditions for these people. People having conservative temperament or when they are employment in an organization cannot achieve risky tasks and for the reason they are not entrepreneurship at their own occupational issues successfully (Williams et al, 1999). The creation, innovation and entrepreneurship are the concepts coming along with the risk. In other words, the creative, innovative and entrepreneurship people can change all risky events into opportunity by accepting the same risky events (Mootana et al, 2010). On the other hand, the sociologists and psychologists consider the sport as a social-cultural phenomenon having a strong bond with all social infrastructures and foundations in this pavement. One of the most important challenges of the sport is subjected to the increase of risks in sport in sport activities in the new century. Although the sport is a recreational and leisure time for all individuals in all communities regarding to the physical activity, these can be considered as the hidden dangers making catastrophic events for the same individuals harmfully. The process of the risk is usually coming along with unsuitable consequences making some harmful results for individuals. In order to decrease or eliminate the related risks, the industry of the sport and leisure times will be required to the implementation of the risk management process as a good managerial system (Baum \& Smith, 2010). In addition, due to the main tasks of the sport offices of Erzurum including the supervision and making the related arrangements of all sport activities regarding to the legislative instructions, the implementation of the plans and programs of the physical training organization should be established based on preparing and adjusting the quality and quantity-based development programs regarding to the physical training and sport issues in the provincial level because this will bring all struggles for giving our country culture and considering all country regulations and legislations as well as the health at sport activities providing all sport locations for using the sport facilitations correctly for the public sections. Among this, having the risk management along with the supervision elements, perception and techniques can make all organizations to reach to their purposes in this field. In other words, the risk management can construct an innovative and creative organization potentially because the type of the suitable risk management in the sport field is a kind of relationship with the creation and entrepreneurship of staffs because the sport management affairs have got some unpredictable events and the researcher of the present study aims at managing whether the entrepreneurship and creativity can control the suitable risk issues or no. In other words, can the risk management be implemented suitably by these individuals? For the reason, there is designed a research in order to respond the question whether there is a relationship between the risk management with creation and entrepreneurship of sport offices of Erzurum city? Alnoor (2005) showed that having correct and sophisticated thinking all about the new management knowledge regarding to the risk management can bring the possibility of the suitable innovation. Coombs (2009) showed that there is a controversial viewpoint between the students, coaches and specialists regarding to good or moderate status of these halls. Coombs (2012) showed that there is no significant difference between the age of managers and rate of risk management behaviors, managers' gender and the rate of the risk management behaviors. But there is a significant relationship between the managers' educational certificate and the rate of the risk management behaviors. He showed that there is a significance relationship between the thinking investment variables (humanistic, communicative and structural investments) and the risk management of enterprises. He showed that there is a positive significance between the thinking investment (humanistic, communicative and structural investments) and risk management of enterprises. Windels \& Stuhlfaut (2014) showed that there is established a significant difference between the building safety status and the establishments in different areas in Tehran. Also, the rate of the managers' conscious is little higher than the average level regarding to the safety importance and risk management of these halls.

\section{Methods and Material}

This study is a descriptive type of study and it also is an applied type of study regarding to its purpose. The variables of the study are as the risk management as the predictor variable, creation and entrepreneurship variables as the criteria variable in this study. Hence, the correlation method is also applied to investigate the relationship between these mentioned variables. 


\subsection{Statistical Sample}

Seventy six Erzurum sport office staffs have been participated in this study.

\subsection{Research Instruments}

\subsubsection{The Questionnaire of Risk Management Evaluation Tool}

This test includes 15 questions measuring the perception of the risk management, risk management techniques and evaluation on the risk. In the present study, the contextual validity of the questionnaires has been confirmed by three specialists of the physical training management field and the internal reliability has been also obtained through alpha Cronbach 0.928.

Rendsip creation questionnaire: This questionnaire includes 30 questions measuring the rate of person's creation into an organization. In the present study, the contextual reliability of the questionnaire has been confirmed by three specialists of the physical training management field and the internal reliability of the same questionnaire has been also obtained by Cronbach alpha 0.725 .

Gibb organizational entrepreneurship questionnaire: In the present study, the contextual validity of the questionnaires has been confirmed by three specialists of the physical training management field and the internal reliability has been also obtained by the use of Cronbach alpha coefficient 0.836 .

\subsection{Data Analysis Method}

Pearson correlation test is applied in order to measure the relationship between the main and minor hypotheses of the present study. The related data is also analyzed by the use of SPSS21 software.

\section{Result}

Table 1. the results of Pearson correlation coefficient to investigate the relationship between the risk management perceptions, risk management techniques; Supervision on risk and the creation of staffs and entrepreneurship

According to table 1, the obtained results have shown that there is a positive significance between the risk management

\begin{tabular}{lccc}
\hline Predictive variables & Category & correlation coefficient & Sig. \\
\hline risk management perceptions & Creativity & 0.267 & 0.001 \\
risk management techniques & Creativity & 0.301 & 0.001 \\
Supervision on risk & Creativity & 0.39 & 0.001 \\
risk management perceptions & entrepreneurship & 0.502 & 0.001 \\
risk management techniques & entrepreneurship & 0.466 & 0.001 \\
Supervision on risk & entrepreneurship & 0.524 & 0.001 \\
\hline
\end{tabular}

perception and the creation, the risk management techniques and supervision on risk, risk management perception, risk management techniques and supervision on risk and entrepreneurship.

Table 2. Results of ANOVA analysis to predict the staffs' creation from risk management variable

\begin{tabular}{lccccc}
\hline Source of Changes & SS & df & MS & F & Sig. \\
\hline Regression & 0.551 & 3 & 0.184 & 4.72 & 0.005 \\
\hline Rest & 2.8 & 72 & 0.039 & & \\
\hline
\end{tabular}

According to above-mentioned tales, due to score F (4.72) and significance level little than 1\%, the resource of changes to predict the creation by the risk management is established in suitable level.

Table 3. Multi-regressions to display the elements of risk management to predict the staffs' creation

\begin{tabular}{llccccc}
\hline Changes of Category & Predictive Variables & B & Coef. Err. & Coef. Stand & T & Sig. \\
\hline Creativity & risk management perceptions & -0.028 & 0.047 & -0.104 & -0.595 & 0.554 \\
\cline { 2 - 7 } & risk management techniques & 0.046 & 0.046 & 0.143 & 1.001 & 0.32 \\
\cline { 2 - 7 } & Supervision on risk & 0.101 & 0.044 & 0.385 & 2.3 & 0.024 \\
\hline
\end{tabular}

According to table 3, the significance level of the perception and risk management techniques elements is higher than 0.05; for the reason, these elements are not able to predict the staffs' creation in this pavement and for the reason, the significance level of the risk supervision is little than 0.05; for the reason, these elements are able to predict the staffs' creation.

Table 4. The results of ANOVA analysis to predict the staffs' entrepreneurship from the risk management variable

\begin{tabular}{llllll}
\hline Source of Changes & SS & df & MS & F & Sig. \\
\hline Regression & 9.96 & 3 & 3.32 & 11.46 & 0.001 \\
\hline Rest & 20.87 & 72 & 0.29 & & \\
\hline
\end{tabular}

According to the above-mentioned tables, due to the score $\mathrm{F}(11.46)$ and significance level lower than $1 \%$, the resource of changes to predict the entrepreneurship is established in suitable level. 
Table 5. Multi-regressions to display the risk management elements coefficients in the prediction of entrepreneurship

\begin{tabular}{llccccc}
\hline Source of Changes & Predictive variable & B & Coe. Stand & Std. Err. & T & Sig. \\
\hline entrepreneurship & Risk management perceptions & 0.129 & 0.127 & 0.161 & 1.01 & 0.313 \\
\cline { 2 - 7 } & Risk management techniques & 0.189 & 0125 & 0195 & 0.133 & 0.133 \\
\cline { 2 - 7 } & Supervision on risk & 0213 & 012 & 029 & 0.058 & 0.058 \\
\hline
\end{tabular}

According to table 5, the significance level of all risk management elements are higher than 0.05 ; thus, these elements are not able to predict the staffs' entrepreneurship.

\section{Discussion and Conclusion}

The results showed that there is a positive significant relationship between the risk management and staffs' entrepreneurship of Erzurum sport offices. This result has been proofed and investigated by the use of Pearson correlation coefficient. Windels \& Stuhlfaut (2014) showed that with the recognition of the risk management and innovation, it can be reached to the performance recovery in this pavement. Also, Slack (2014) showed that there is a positive significant relationship between the share efficacy and the status of the banking risk management. Aaron (2010) also concluded that the risk management can be implementable increasing the rate of the projects success economically. Hsiao (2015) showed that the risk management with creation will be led to the value in the field of finance and operational issues. Valentine and Zibeck (2014) concluded that the conscious of the risk management methods and applications can make new entrepreneurship in this pavement. Christine and Scarlet (2014) showed that the personal risk attitude is related with the ability of creation and the selection of the creative concept in the evolution and idea-making of the engineering projects. The main reason for the adaption of the above-mentioned results with the present study subjected to the fact that the main necessary case for implementing the risk management into an organization is having creative temperament between staffs and the entrepreneurship attitudes in this pavement. Theoretically, the creation and innovation as well as the entrepreneurship are subjected to those concepts that they are always coming along with risky affairs. In other words, the creative and innovative people can obtain the opportunities with risk-ability (Mootana et al, 2010). Also, the entrepreneurship is the process that is makes a new element along with the new value using the creation, time, resource and other factors (the same). On the other hand, the entrepreneurship culture is also subjected to follow all opportunities trying to meet all requirements through the process of the creation and innovation and this will lead to establish a new occupational opportunit. Indeed, the construction and application of opportunities are the main basic concepts of the entrepreneurship and these kinds of opportunities will be followed only by the risky affairs. The higher expectation of the common activities can also praise all entrepreneurships to confront with these issues (Windels \& Stuhlfaut, 2014). The results showed that there is a positive significant relationship between the risk management perception with creation of staffs in Erzurum sport offices. Also, Slack (2014) showed that there is a positive significant relationship between the share efficacy and the status of the banking risk management. Aaron (2010) also concluded that the risk management can be implementable increasing the rate of the projects success economically. Hsiao (2015) showed that the risk management with creation will be led to the value in the field of finance and operational issues. Valentine and Zibeck (2014) concluded that the conscious of the risk management methods and applications can make new entrepreneurship in this pavement. Christine and Scarlet (2014) showed that the personal risk attitude is related with the ability of creation and the selection of the creative concept in the evolution and idea-making of the engineering projects. The main reason for the adaption of the above-mentioned results with the present study subjected to the fact that the main necessary case for implementing the risk management into an organization is having creative temperament between staffs and the entrepreneurship attitudes in this pavement. Theoretically, the creation and innovation as well as the entrepreneurship are subjected to those concepts that they are always coming along with risky affairs. In other words, the creative and innovative people can obtain the opportunities with risk-ability (Mootana et al, 2010). The common method is that the successes should be praised and all failures have to be punished in this pavement. This will make all individuals to prevent any failures and they have to follow only those tasks having with the highest success and for the reason this will also prevent these individuals to achieve any risky affairs in this regard. The creative person looks at the failure as a necessity for the lifetime because the main obtain of all experiences has been dependent on the failures (Harwell, 2013). The results showed that there is a positive significant relationship between the risk management techniques with staffs' creation of Erzurum sport offices. This result is proofed and confirmed by the use of Pearson correlation coefficient. Aaron (2014) also concluded that the risk management can be implementable increasing the rate of the projects success economically. Hsiao (2015) showed that the risk management with creation will be led to the value in the field of finance and operational issues. Windelse and Stelfot (2014) showed that the agency managers are very tend to make risky affairs and this will make them to profit from the creative identity and the clarified communications regarding to the type of creative job into an organization. Along this, the risk management at sport is subjected to the responsibility that it can be useful for determining and recognizing the methods for applying against all threats (Frust, 2012). Among this, the existence of the creation in applying the risk management techniques can be a great solution in this path. The results showed that the determination of the relationship between the supervision on risk with the creation of staffs can be related together in the Erzurum sport offices. This result is proofed and investigated 
by the use of Pearson correlation coefficient. Alnoor (2009) showed that along with correct approaches based on the modern knowledge of the risk management, the possibility of the suitable innovation can be achieved in this pavement. Frust (2012) also showed that the risk management behaviors can be considered in seven conceptual level of the supervision, medical and therapeutically affairs, establishments, transformation of risk, transportation, safety of instruments and the application and training the staffs into the private and governmental clubs. The main reason for the adaptation of the results with the present results is subjected to the fact that the type of supervision on risks depends on the creation because when confronting with dangers, the creation can be very useful for making the risk management in order to control the same danger. Theoretically, the implementation of programs in a public location is an impossible task particularly when the supervision of the risk is subjected to the man. Today, the sport is considered as an industrial profession professionally in all over the world; among this, those sport being achieved into the sport halls have their own fanatics and supporters. The establishment and conduction of the sport clubs with suitable planning issues can lead to the highest value among all users and social supporters meeting all public expectations and safety and health in this pavement. Since the elimination of all damages and catastrophic events of the sport affairs is to some extent impossible but the main key of confronting with risk and the reduction of the predictable damages can be achieved in this pavement; the risk management is one of the inseparable parts of the supervision and predictable affairs (Frust, 2012).

The results showed that there is a positive significant relationship between the risk management perception and the staffs' entrepreneurship in Erzurum sport offices. Valentine and Zibeck (2014) concluded that the conscious of the risk management methods and application of the same process can be a great solution of the recent and new entrepreneurship. Po (2014) showed that the different schools have significant difference in the tendency towards the entrepreneurship. Also, the different perceptions from the dangers for the entrepreneurship can influence on the rate of the same entrepreneurship in this regard. The main reason for the adaptation of the results with the present study subjected to the fact that the risk management for an organization is very important increasing the innovative and creative temperament of all staffs functionally. Theoretically, one of the most outstanding features of the entrepreneurship is subjected to the literature of the entrepreneurship emphasizing on the risk-ability of people in this case. Indeed, the entrepreneurships are those individuals that they tend to have independent temperament being responsible for the occupational issues. The entrepreneurships are more responsible and self-autonomous ones (Mootana et al, 2010). The entrepreneurships should be risky because by this method they can tolerate all about failures and problems and then they will reach to the success. The government should also be ready to support these entrepreneurships providing the necessary investment for these individuals. People having the most conservative temperament will not get succeeded in the process of entrepreneurship (Williams et al, 1999).

The results showed that there is a positive significant relationship between the risk management techniques and the staffs' entrepreneurship in Erzurum sport and organization. Valentine and Zibeck (2014) concluded that the conscious of the risk management methods can be a great solution for the process of entrepreneurship. The main reason of the adaptation of the results may be subjected to the fact that the construction of the new methods can increase the temperament of the entrepreneurship. Theoretically, the entrepreneurship person is a risk-able person trying to achieve more risky tasks. In other words, this person has to be productive for all commodities such as the land, job force and investment and this kind of person is called " entrepreneurship" (Thompson and Geoff, 2000). The entrepreneurship is a process that it uses the creation along with a new element for making new value and this can be also done by the use of time, resources and danger (the same). The results showed that there is a positive significant relationship between the supervision on risk with entrepreneurship of staffs in Erzurum sport organization. Po (2014) showed that the different schools have significant difference in the tendency towards the entrepreneurship. Also, the different perceptions from the dangers for the entrepreneurship can influence on the rate of the same entrepreneurship in this regard. The main reason for the adaptation of the results with the present study subjected to the fact that the risk management for an organization is very important increasing the innovative and creative temperament of all staffs functionally. Theoretically, one of the most outstanding features of the entrepreneurship is subjected to the literature of the entrepreneurship emphasizing on the risk-ability of people in this case. Indeed, the entrepreneurships are those individuals that they tend to have independent temperament being responsible for the occupational issues. In the time of investing on an entrepreneurship, the creation and innovation should be evaluated for obtaining the highest investment in versus the expectations for losing the same investment. In this kind of status, the general purpose is to increase the wealth of the entrepreneurship praising the same entrepreneurship to make risk for providing a profitable opportunity in this pavement. In contrast, the dangerous risk is coming along with a potential damage and there is no making an opportunity for compensating the same damage in this regard. For example, it can be paid attention to the safety and investment for obtaining the same safety as a dangerous risk in this regard. Indeed the investment of these kinds of statuses would have some harmful issues for keeping the recent conditions (Mootana et al, 2010). Therefore, the risk is not merely defined as the clear and transparent categorization for making the related profits but also it should be established based on conditions being perceivable in this path; an entrepreneurship has to consider the profitable risk, 
too. When the wealth of the same entrepreneurship is increased, the probability of the dangerous risk and the damage tolerance will be also decreased in this regard (the same). The results showed that among the risk management elements, the supervision on risk can predict the creation of staffs into the Erzurum sport organization. Frust (2012) showed that the risk management behaviors have been considered in seven conceptual levels of the supervision, medical affairs, establishments, warning and risk transformation, transportation, safety of instruments and application and training staffs in private and governmental clubs. The main reason for the adaptation of the results may be subjected to the fact that when confronting with risks the application of the recent resources can assist on the risk management efficiently. Theoretically, the risk management is not a magical formula for eliminating the events but also it can reduce the number of the catastrophic events in this field. Today most organizations have paid attention to the importance of the risk management operations but putting the politics and its policies into the related process has made the process to confront with many various problems in this pavement. For example, the lack of enough knowledge about the management, lack of new establishments, lack of risk management planning and the lack of experienced staffs in the recent years have been made some problems for individuals participations in sport affairs (Frust, 2012). For the reason, by the use of the risk management along with creation and innovation, it can reach to fill all gaps between the recent deficiencies in entrepreneurship issues managing the sport management in this regard. The results showed that none of the elements are able to predict the staffs' entrepreneurship from all risk management elements in Erzurum sport organization. There is no established any study to confirm the related results.

\section{References}

Aaron, T. C. (2014). Factors affecting the performance levels of risk management behaviors of Florida high school athletic directors. Phd thesis, the Florida state university college of education.

Alnoor, B. (2009). Risk management, corporate governance and management accounting, Emerging interdependencies. Management Accounting Research, 20, 2-5. https://doi.org/10.1016/j.mar.2008.11.002

Baum, R., \& Smith, J. (2011). The Practical Intelligence Of potential Entrepreneurs. Smith School of Business University of Maryland College Park.

Brown, D. A., \& Sawyer, T. H. (1998). Risk management study of division II Athletic directors. Journal of Legal Aspects of Sport, 8(1), 24-32. https://doi.org/10.1123/jlas.8.1.25

Christine, A. T., \& Scarlett, R. M. (2014). The Role of Individual Risk Attitudes on the Selection of Creative Concepts in Engineering Design, Volume 7: 2nd Biennial International Conference on Dynamics for Design; 26th International Conference on Design Theory and Methodology Buffalo, New York, USA, August 17-20.

Coombs, M. (2009). Notes on critical care - review of seminal management and leadership papers in the United Kingdom. Intensive and Critical Care Nursing, 25(3), 128-132. https://doi.org/10.1016/j.iccn.2009.01.002

Culp, T., \& Christopher, L. (2001). The Risk Management Process, John Wiley \& Sons.

Dimitriadi, A., \& Dimitriadi, S. (2007). A conceptual model of risk management and its importance for sport and Leisure. SMIJ, 3,

Drucker, P. F. (1995). Managing in a time of Great Change. New York: Dutton, Truman Books. Tally

Furst, R. M. (2012). An exploration of corporate entrepreneurship: Venturing signatures and their underlying dynamics. From www. Wilkes.Edu/Include /Academics /Gradbulletin_0304.Pdf

Harrison, M., Egbert, P., \& Phil, T. (2003). How Value Engineering and Changed the Design of Methanol Recovery in the Malampaya Onshore Gas Plant, Accessed Nov, 02, www.fwc.com/publication.

Harwell, R. (2013). A study of effective risk management practices in higher education. Doctoral dissertation, Baylor University, Waco, Texas, Copyright by proQuest Information and Learning Company.

Hsiao, R. (2015). Analysis of risk management practices and litigation status in aquatic centers. Phddissertation, Florida State University College of Education, Copyright by proQuest Information and Learning Company.

Mootanah, D. P., Russull, P. B., \& Mike, J. (2010). A Strategy for Management Project Risk in Value Management Studies, SAVE International Conference proceeding.

Po-Chang, T. (2014). The effect of Management Education and Risk Tolerance Attitude on Students' Entrepreneurship Willingness Affected, http://ethesys. lib.mcu.edu.tw/ETD-db/ETD-search/view_etd?URN=etd-0627114-165612

Singh, C., \& Surujlal, J. (2010). Risk management practices of high scholl sport coaches and administration, South African journal for research in sport. Physical Education and Recreation, 32(1), 107-119.

Slack, D. A. (2014). Risk management health care practices in NCAA athletic programs. Doctoral dissertation, 
Department of Exercise and Sport Science. University of Utah, Copyright by proQuest Information and Learning Company.

Thompson, J. (2000). Social entrepreneurship: A new look at the people and the Potential, Management Decision, 38(5). https://doi.org/10.1108/00251740010340517

Valentin, M. G., \& Zhibek, B. R. (2014). effective mechanisms development for risk management in business entrepreneurship, Actual Problems of Economiics, 5(155), 2014

Vesper, K. H., \& Gartner, W. B. (2000). University Entrepreneurship Programs, University of Southern California, Marshall School of Business.

Williamson, O. E. (1991). Strategizing, Economizing, and Economic Organization. Strategic Management Journal, 12, 75-94. https://doi.org/10.1002/smj.4250121007

Windels, K., \& Stuhlfaut, M. W. (2014). Confined Creativity: The Influence of Creative Code Intensity on Risk Taking in Advertising Agencies, Journal of Current Issues \& Research in Advertising, 35(2). https://doi.org/10.1080/10641734.2014.899530

\section{Copyrights}

Copyright for this article is retained by the author(s), with first publication rights granted to the journal.

This is an open-access article distributed under the terms and conditions of the Creative Commons Attribution license which permits unrestricted use, distribution, and reproduction in any medium, provided the original work is properly cited. 